\title{
TAXONOMY AND ANTIMICROBIAL ACTIVITY OF STREPTOSPORANGIUM STRAIN SG163 ISOLATED FROM A SAHARAN SOIL
}

\author{
K. Bouti ${ }^{1}$, H. Boudjella ${ }^{* 1}$, N. Bouras ${ }^{1,2}$, A. Zitouni $^{1}$, F. Mathieu ${ }^{3}$, N. Sabaou ${ }^{1}$ \\ ${ }^{1}$ Laboratoire de Biologie des Systèmes Microbiens, Ecole Normale Supérieure de \\ Kouba, Alger, Algeria. \\ ${ }^{2}$ Département de Biologie, Faculté des Sciences de la Nature et de la Vie et Sciences de \\ la Terre, Université de Ghardaïa, BP 455, Ghardaïa 47000, Algeria. \\ ${ }^{3}$ Laboratoire de Génie Chimique, Université de Toulouse, CNRS, Toulouse, \\ France. \\ *Corresponding author: Prof Hadjira Boudjella \\ h-boudjella@live.fr
}

(Received February 2017- Accepted September 2018)

\section{ABSTRACT}

K. Bouti, H. Boudjella, N. Bouras, A. Zitouni, F. Mathieu, N. Sabaou. 2019. Taxonomy and antimicrobial activity of Streptosporangium strain sg163 isolated from a saharan soil. Lebanese Science Journal. 20(1): 35-54.

In a continuing search for new antimicrobial products from actinobacteria collected in Algerian Saharan soils, an isolate of actinobacteria, designated Sg163, was selected for its interesting antimicrobial activity. The isolate was identified to the genus Streptosporangium by phenotypic and molecular criteria. The cultural and physiological characterizations as well as phylogenetic analysis indicated that the isolate was different from known members of the genus Streptosporangium. Analysis of the 16S rRNA sequence showed 97.09 to $98.27 \%$ similarity with those of Streptosporangium type strains. The strain $\mathrm{Sg} 163$ produced antifungal and antibacterial activities on several culture media. The highest antimicrobial activities were obtained in ISP2 medium. Three active products C1, C2 and C3 with both antifungal and antibacterial activities were isolated and purified by chromatographic methods with $C 2$, as the major compound. The data of the infrared spectroscopy and the chemical revelations, suggested that the active molecules were glycosylated aromatic compounds. 
Keywords: Actinobacteria, Streptosporangium, Taxonomy, antimicrobial activity.

\section{INTRODUCTION}

The search for new antimicrobial agents is still required because of the increasing number of antibiotic-resistant strains of pathogenic microorganisms (Solecka et al., 2012; Demain and Sanchez, 2009; Fischbach and Walsh, 2009). Microbial natural products continue to represent an important route to the discovery of new antimicrobial compounds (Genilloud, 2014). Among microorganisms, actinobacteria, which are also named actinomycetes, represent a diverse and valuable resource of beneficial natural products (Kurtböke, 2012). The genus Streptomyces is the dominant actinobacteria in soils and the source of a broad range of bioactive compounds. However, other rare actinobacteria genera such as Streptosporangium, Saccharothrix, Actinomadura, Micromonospora, Nocardiopsis and Nocardia have proved to be important sources of industrially useful antibiotics (Kurtböke, 2012; Tiwari and Gupta, 2012; 2013; Genilloud et al., 2011). In this context, the research in our laboratory was focused on the isolation of new antimicrobial compounds produced by soil actinobacteria others than Streptomyces. Several Saharan soil samples collected in arid ecosystems were explored, and many novel taxa and new bioactive molecules were obtained (Boubetra $e t$ al., 2013; Meklat et al., 2013; Boudjella et al., 2007; Badji et al., 2006; Zitouni et al., $2004 \mathrm{a}, \mathrm{b})$.

As part of this screening program, we were interested by members of the genus Streptosporangium, which are known to produce several secondary metabolites (Inahashi et al., 2011; Boudjella et al., 2010; Platas et al, 1999; Cooper et al., 1990; Hurley et al., 1979). During our initial survey, the antimicrobial activity of an isolate drew our attention as it produced antimicrobial activities against fungi and bacteria on several culture media. In the present paper, we reported the methods used for isolation and identification of this isolate as well as the purification and the partial characterization of the produced antibiotics.

\section{Strain isolation}

\section{MATERIALS AND METHODS}

Actinobacterium $\operatorname{Sg} 163$ was isolated by the dilution agar plating method from a Saharan soil sample collected in Adrar (south Algeria, latitude $27^{\circ} 53^{\prime} \mathrm{N}$, longitude $0^{\circ}$ $17^{\prime} \mathrm{W}$, Height $263 \mathrm{~m}$ ). The dry soil sample was pretreated at $120^{\circ} \mathrm{C}$ for $1 \mathrm{~h}$ (Nonomura and Ohara, 1969a), serially diluted and spread onto chitin vitamin agar medium (Hayakawa and Nonomura, 1987) supplemented with cycloheximide $(50 \mu \mathrm{g} / \mathrm{ml})$. The plates were incubated at $30{ }^{\circ} \mathrm{C}$ for 14 days. 


\section{Taxonomic studies of the strain}

Taxonomic studies of isolate $\mathrm{Sg} 163$ were performed according to the standards for Streptosporangium (Quintana and Goodfellow, 2012; Holt et al., 1994).

The morphology of strain Sg163 was observed using a Zeiss light microscope. The cultural characteristics were studied using 14-day-old cultures grown on International Streptomyces Project (ISP) media (Shirling and Gottlieb, 1966), including yeast extract-malt extract agar (ISP2), oatmeal agar (ISP3) and inorganic salts-starch agar (ISP4), and also on oatmeal-yeast extract-glycerol agar (OYG) (Quintana and Goodfellow, 2012). The colors of aerial mycelium, substrate mycelium and the diffusible pigment were determined with the ISCC-NBS centroid color charts (National Bureau of Standards, 1964).

To obtain biomass for chemotaxonomic analyses, cultures were grown in ISP2 broth for 8 days at $30^{\circ} \mathrm{C}$. The cultures were then harvested by centrifugation and washed three times with distilled water. Diagnostic cell-wall amino acids, sugars from wholecell hydrolysates and membrane phospholipids were analyzed using the methods of Becker et al. (1964), Lechevalier and Lechevalier (1970) and Minnikin et al. (1977), respectively.

The physiological study consisted of 75 tests including the degradation of 24 carbohydrate compounds evaluated on C1 medium (Nonomura and Ohara, 1969b), the degradation of 12 organic compounds: Tween 80 (Sierra, 1957), adenine, guanine, xanthine, hypoxanthine, casein, tyrosine, testosterone (Goodfellow, 1971), gelatin, starch, esculin and arbutin (Marchal et al., 1987), the decarboxylation of 9 organic acids (Gordon et al., 1974) and the production of melanoid pigments on ISP6 and ISP7 media (Shirling and Gottlieb, 1966) and nitrate reductase (Marchal et al., 1987). The growth was examined on glucose-yeast extract agar (GYEA) medium supplemented with 11 different antibiotics (Athalye et al., 1985) and at $\mathrm{pH} 5,7$ and 9, and at 42 and $50^{\circ} \mathrm{C}$. Growth in the presence of other inhibitory compounds (w/v), including sodium azide, $0.001 \%$, sodium chloride, $1,2,3,5$ and $7 \%$, potassium tellurite, $0.01 \%$ and $0.05 \%$, phenol, $1.5 \%$ and lysozyme, $0.005 \%$ was also tested in the same medium (Gordon and Barnett, 1977; Athalye et al., 1981).

For DNA preparation, PCR amplification and sequence determination, isolate $\mathrm{Sg} 163$ was grown at $30^{\circ} \mathrm{C}$ for 7 days in a $500 \mathrm{ml}$ shake flask, containing $100 \mathrm{ml}$ of ISP2 medium. DNA was extracted using the procedure described by Liu et al. (2000).

PCR amplification of the 16S rRNA of strain Sg163 was performed using two primers: $\quad 27 \mathrm{f}$ (5'-AGAGTTTGATCCTGGCTCAG-3') and 1492r (5'GGTTACCTTGTTACGACTT-3'). Each $50 \mu \mathrm{l}$ amplification reaction (Invitrogen kit) contained 1X PCR buffer (10 mM/lTris- $\mathrm{HCl}, 50 \mathrm{mM} / \mathrm{l} \mathrm{KCl}, \mathrm{pH} 9.0$ at $\left.25{ }^{\circ} \mathrm{C}\right), 1.5 \mathrm{mM} / \mathrm{l}$ $\mathrm{MgCl}_{2}, 200 \mu \mathrm{M} / 1$ of each $\mathrm{dNTP}, 1 \mu \mathrm{M} / 1$ of each primer, $1.25 \mathrm{U}$ of Taq DNA 
polymerase and $1 \mu \mathrm{l}(500 \mathrm{ng})$ of the purified DNA. The amplification was performed on a STRATAGENE RoboCycler Gradient 96, according to the following profile: denaturation of the target DNA at $98^{\circ} \mathrm{C}$ for $3 \mathrm{~min}$, after which $T a q$ polymerase was added, followed by 30 amplification cycles at $94^{\circ} \mathrm{C}$ for $1 \mathrm{~min}$, primer annealing at $52^{\circ} \mathrm{C}$ for $1 \mathrm{~min}$, and primer extension at $72^{\circ} \mathrm{C}$ for $5 \mathrm{~min}$. At the end of the cycling, the reaction mixture was held at $72^{\circ} \mathrm{C}$ for $5 \mathrm{~min}$ and then cooled to $4^{\circ} \mathrm{C}$. Reaction products were electrophoresed on a $1 \%$ agarose gel and checked with ethidium bromide under UV fluorescence.

The PCR product was sequenced by MilleGen Company (Toulouse, France) with an automatic sequencer and the same primers as above. The obtained 16S rRNA sequence was compared for similarity level with the reference species of bacteria contained in genomic database banks, using the sequences present in public sequence databases as well as the EzTaxon-e server (http://eztaxon-e.ezbiocloud. net/ (Kim et al., 2012).

Phylogenetic and molecular evolutionary analyses were conducted using MEGA version 5 (Tamura et al., 2011). The 16S rRNA sequence of strain Sg163 was aligned using the CLUSTAL W program (Thompson et al., 1994) against corresponding nucleotide sequences of representatives of the genus Streptosporangium retrieved from EzTaxon. Phylogenetic tree was inferred by the neighbor joining method (Saitou and Nei, 1987). Evolutionary distance matrices were generated as described by Jukes and Cantor (1969). Tree topologies were evaluated by bootstrap analysis (Felsenstein, 1985) based on 1000 resamplings of the neighbor joining dataset.

\section{Antimicrobial activity}

The antimicrobial activity spectrum of strain Sg163 was examined during the primary screening for potential antimicrobial activities by the conventional cross-streak method (Williston et al., 1947) on ISP2 medium (Shirling and Gottlieb, 1966). Strain Sg163 was inoculated in a straight line on different agar plates of $90 \mathrm{~mm}$ diameter and incubated at $30^{\circ} \mathrm{C}$ for 14 days to allow it to secrete antibiotics into the medium. After incubation, target organisms were seeded in crossed streaks to Sg163 culture. The plates were then incubated for $48 \mathrm{~h}$ for fungi and $24 \mathrm{~h}$ for yeasts and bacteria. The antimicrobial activity was evaluated by measuring the distance of inhibition between target microorganisms and actinomycete colony margins. Tests were conducted in triplicate.

The test organisms included fungi (Aspergillus carbonarius M333, A. westerdijkiae NRRL 3174, Botrytis cinerea, Fusarium culmorum 3288, F graminearum 5883, F. sporotrichinoides 13440, F. verticilloides 6442, Geotrichum candidum, Umbelopsis ramanniana NRRL 1829, Penicillium citrinum P1843, P. verrucosum P1850, Pythium irregular PY120, and Sclerotium sclerotiorum S358), yeasts (Candida albicans C200, Candida albicans C224, Kluyveromyces lactis K258, Rhodotorula 
mucilaginosa R321, and Saccharomyces cerevisiae ATCC 4226), Gram-positive bacteria (Bacillus subtilis ATCC 6633, Listeria monocytogenes CIP 82110, Staphylococcus aureus CIP 7625 and Micrococcus luteus ATCC 9314) and Gramnegative bacteria (Escherichia coli ATCC 10536, Pseudomonas aeruginosa ATCC 27853 and Klebsiella pneumoniae CIP 8291). Most of these test organisms are phytopathogenic, or human pathogenic or toxigenic.

\section{Effect of culture media on the production of antimicrobial activities}

To determine the optimal culture medium for antibiotic production, five complex culture media pre-inoculated with Sg163 were investigated. The selected media were: ISP2 (Shirling and Gottlieb, 1966) containing glucose, yeast extract and malt extract, Bennett medium (Warren et al., 1955) composed of glucose, meat extract, yeast extract and peptone, ISP4 (Shirling and Gottlieb, 1966) containing starch and inorganic salts, the medium of Gilpin et al. (1995) designated M4 and containing glycerol, yeast extract, malt extract and peptone of soya, and the medium of Omura et al. (1989) designated M5 and containing glucose, meat extract, dry yeast and peptone.

The media were prepared in 500-ml Erlenmeyer flasks containing $100 \mathrm{ml}$ of medium. The $\mathrm{pH}$ was adjusted to 7.3 prior to sterilization. For the seed culture, isolate $\mathrm{Sg} 163$ was grown on ISP2 agar for 7 days at $30^{\circ} \mathrm{C}$. The mycelium was scraped and inoculated into 250-ml Erlenmeyer flasks containing $50 \mathrm{ml}$ of each medium. After 4 days of growth on a rotary shaker $(250 \mathrm{rpm})$ at $30^{\circ} \mathrm{C}$, aliquots $(5 \%, \mathrm{v} / \mathrm{v})$ of the seed culture were transferred into 500-ml Erlenmeyer flasks containing $100 \mathrm{ml}$ of the medium. The cultures were incubated on a rotary shaker $(250 \mathrm{rpm})$ at $30^{\circ} \mathrm{C}$. The time course fermentation was carried out for 13 days. The antimicrobial activity in the culture broths was tested by the agar well diffusion method using Umbelopsis ramanniana NRRL 1829, Saccharomyces cerevisiae ATCC 4226 and Micrococcus luteus ATCC 9314 as target organisms. A volume of $20 \mathrm{ml}$ of nutrient agar was inoculated with $100 \mu \mathrm{l}$ of microbial suspension containing $10^{8} \mathrm{CFU} / \mathrm{ml}$ of the target organism and then poured onto a Petri dish and allowed to solidify at room temperature for $30 \mathrm{~min}$. Wells of $10 \mathrm{~mm}$ diameter were aseptically bored into the culture medium and $200 \mu \mathrm{L}$ of each culture filtrate were added to each well. The antimicrobial activity production, the growth (dry weight of mycelium) and the $\mathrm{pH}$ were measured every $24 \mathrm{~h}$.

\section{Extraction and purification of antimicrobial products}

For the production of antibiotics, fermentations were carried out in 500-ml Erlenmeyer flasks containing $100 \mathrm{ml}$ of ISP2 broth $\left(250 \mathrm{rpm}, 30^{\circ} \mathrm{C}, 7\right.$ days $)$. The antimicrobial activity was obtained from 51 of culture broth and purified by various separation steps including solvent extraction, preparative silica gel plates and high performance liquid chromatography (HPLC). The antimicrobial compounds were extracted on the day of optimal production rate. The culture broth was centrifuged (3000 $g, 15 \mathrm{~min}$ ) to remove the biomass. The cell-free supernatant was extracted with an equal 
volume of $n$-butanol. This solvent was selected in a preliminary test, where 4 solvents were tested. Each volume of $60 \mathrm{ml}$ of the cell free supernatant was extracted with an equal volume of the following organic solvents: $n$-hexane, dichloromethane, ethyl acetate and $n$-butanol. The organic and aqueous phases were recuperated separately and concentrated to dryness (Laborota 4000 rotavapor). The organic extracts were recuperated in methanol, and the aqueous ones in water. Both organic and aqueous extracts were tested for their antimicrobial activity by the paper disk diffusion method against Umbelopsis ramanniana, Saccharomyces cerevisiae and Micrococcus luteus. The highest antimicrobial activity was obtained with $n$-butanol. Furthermore, no antiyeast activity was detected in the organic extracts. It remains in the aqueous phases. Subsequently, we were interested by the butanolic extract, which contained both antifungal and antibacterial activities. The remaining culture filtrate was extracted with $n$-butanol for subsequent purification.

Preparative chromatography with silica gel plates (Merck Art. 5735, Kiesselgel $60 \mathrm{~F} 254$ ) was used for the partial purification of antimicrobial products. A dry crude extract, dissolved in methanol, was spotted and developed in the solvent system $n$ butanol-acetic acid-water (B.A.W.) (3:1:1, v/v). The developed TLC plates were air dried overnight to remove all traces of solvents. The separated compounds were visualized under UV at $254 \mathrm{~nm}$ (absorbance) and at $365 \mathrm{~nm}$ (fluorescence) and the active spots detected by bioautography (Betina, 1973) on silica gel plates seeded with Umbelopsis ramanniana or Micrococcus luteus. In this method, the plates were placed on a glass support in a polyethylene box $(22 \times 24 \mathrm{~cm})$. A sheet of filter paper was placed at the bottom of the box and impregnated with about $30 \mathrm{ml}$ of sterile water to maintain a moist atmosphere and thereby delay the desiccation of the agar during incubation. The device was then sterilized for $1 \mathrm{~h}$ under UV at $254 \mathrm{~nm}$. A volume of fused $50 \mathrm{ml}$ of semi-solid ISP2 (containing $7 \mathrm{~g} / \mathrm{l}$ agar) was inoculated with $2 \mathrm{ml}$ of a target organism suspension. This medium was uniformly distributed with a sterile pipette on the silicagel plates. After solidification of the agar, plates were placed at $4{ }^{\circ} \mathrm{C}$ for $2 \mathrm{~h}$ to allow the diffusion of antibiotic activity in the medium and then incubated at $30{ }^{\circ} \mathrm{C}$. The retention factor (Rf) of the active spot was measured after 24 to $48 \mathrm{~h}$.

The final purification was carried out with a Waters HPLC system equipped with a C18 column (Uptisphere UP 5 ODB, $250 \mathrm{~mm} \times 7.8 \mathrm{~mm}$, Interchim), a mobile phase with a continuous gradient (linear curve) solvent system from 20 to $75 \% \mathrm{v} / \mathrm{v}$ methanol in water, a flow rate of $1.5 \mathrm{ml} / \mathrm{min}$ and UV detection at $220 \mathrm{~nm}$. The pure compounds were collected separately, concentrated and bioassayed against the indicator organisms Umbelopsis ramanniana and Micrococcus luteus.

\section{Chemical characterization of antimicrobial activity}

The pure antimicrobial compounds were revealed on silica gel TLC plates with several chemical agents including ninhydrin, sulfuric acid-naphtoresorcinol, nitro-4anilin, ferrous iron chloride, formaldehyde-sulfuric acid and vanillin-sulfuric acid 
(Merck). The UV-vis absorption spectra of the active molecules were determined with a Shimadzu UV 260 spectrophotometer. For the major compound, infra red spectrum was obtained with Shimadzu IR 470 spectrometer and the mass spectrum was recorded on ion-trap mass spectrometer (Finnigan MAT, San Jose, California, USA), equipped with a nanospray ion ESI source (negative ion mode).

\section{RESULTS AND DISCUSSION}

\section{Strain identification}

Isolate $\operatorname{Sg} 163$ produced aerial mycelium with spherical sporangia. The sporangia were commonly 6-10 $\mu \mathrm{m}$ in diameter. Colonies of $\mathrm{Sg} 163$ grown on various media at $30^{\circ} \mathrm{C}$ for 14 days were observed to be $5-10 \mathrm{~mm}$ in diameter, circular and smooth. It grew well on ISP2 and OYG and weak on ISP3 and ISP4 media. The mycelium was stable and not fragmented. The aerial mycelium was pinkish white in color on most of the media used. The substrate mycelium was yellowish brown and produced a yellow diffusible pigment on all used media.

Cell-wall hydrolysate of isolate Sg163 contained meso-diaminopimelic acid but not glycine. The whole-cell hydrolysates contained madurose as the characteristic sugar. From these results, strain $\mathrm{Sg} 163$ was considered to have a type III B cell wall (Lechevalier and Lechevalier, 1970). The phospholipids consisted of phosphatidylethanolamine and an unknown compound containing glucosamine. This pattern corresponds to the phospholipid type PIV (Lechevalier et al., 1977).

Based on the morphological and chemical characteristics, isolate Sg163 was identified as a member of the genus Streptosporangium.

The results from the physiological study indicated that strain $\mathrm{Sg} 163$ was positive for the utilization of casein, gelatin, starch, tyrosine, arabinose, cellobiose, dextrin, fructose, galactose, glucose, lactose, maltose, mannitol, mannose, rhamnose and trehalose. The strain was negative for the utilization of adenine, arbutin, esculin, testosterone, hypoxanthine, adonitol, dulcitol, erythritol, glycerol, inositol, melibiose, raffinose, saccharose and sorbitol. B vitamins were not required for growth. Melanoid pigments were not produced on ISP6 and ISP7 media. Sodium acetate and pyruvate were degraded. The other sodium salts (butyrate, citrate, oxalate, propionate, succinate and tartrate) were not degraded. Strain $\mathrm{Sg} 163$ was resistant to chloramphenicol (25 $\mathrm{mg} / \mathrm{l})$, cycloserine $(10 \mathrm{mg} / \mathrm{l})$, erythromycin $(10 \mathrm{mg} / \mathrm{l})$, gentamicin $(5 \mathrm{mg} / \mathrm{l})$, oxytetracycline $(25 \mathrm{mg} / \mathrm{l})$, penicilline $(25 \mathrm{mg} / \mathrm{l})$, rifampicin $(5 \mathrm{mg} / \mathrm{l})$, streptomycin $(10$ $\mathrm{mg} / \mathrm{l})$, vancomycin $(5 \mathrm{mg} / \mathrm{l})$ and potassium tellurite $(0.005 \%$ and $0.01 \%)$, but was sensitive to kanamycin $(25 \mathrm{mg} / \mathrm{l})$, novobiocin $(10 \mathrm{mg} / \mathrm{l})$, crystal violet $(0.05 \%)$, lysozyme $(0.005 \%)$, phenol $(1.5 \%)$ and sodium azide $(0.001 \%)$. The optimum growth was at $30^{\circ} \mathrm{C}$ and at $\mathrm{pH}$ 7.3. The strain was not able to grow at $\mathrm{pH} 5$ and 9 , and at 42 and $50^{\circ} \mathrm{C}$. 
The nearly complete 16S rRNA gene sequence (1446 nucleotides) of strain Sg163 was determined and deposited in GenBank under the accession number EF369475. Alignment of this sequence with reported 16S rRNA gene sequences in EzTaxon confirmed the identification of strain Sg163 to the genus Streptosporangium. The phylogenetic tree (Figure 1) showed the position of strain Sg163 within the type species of Streptosporangium. The similarity values between strain Sg163 and the type strains in the genus Streptosporangium ranged between $97.1 \%$ and $98.3 \%$. The species showing the highest similarity values to strain $\mathrm{Sg} 163$ were $S$. canum HBUM $170018^{\mathrm{T}}$, S. roseum DSM 43021 ${ }^{\mathrm{T}}$, S. album DSM $43023^{\mathrm{T}}$ and $S$. vulgare DSM $43802^{\mathrm{T}}$ (between 98.1 and $98.3 \%$ ). Table 1 summarizes the differential characteristics of strain Sg163 and the related strains.

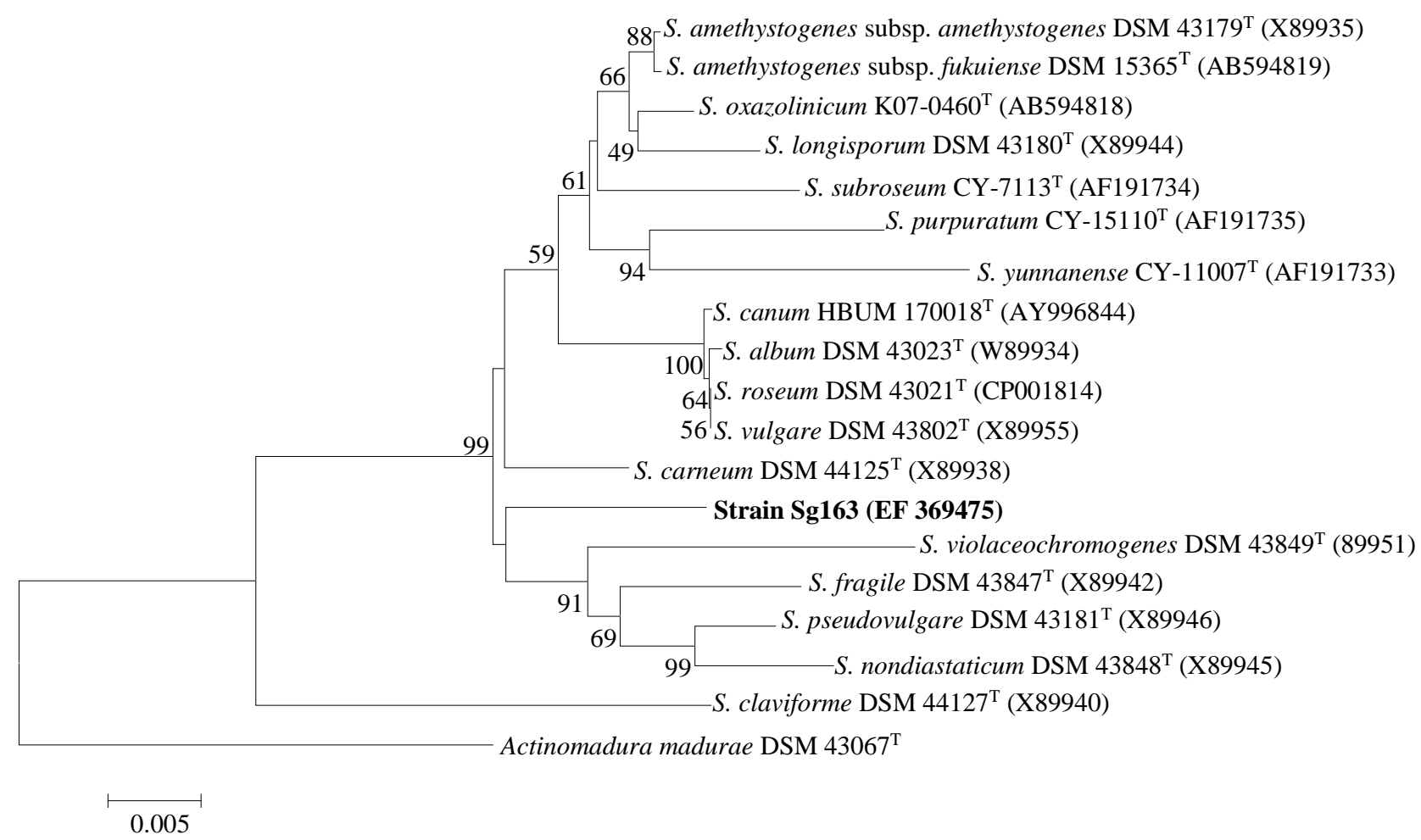

Figure 1. Neighbor-joining phylogenetic tree, based on 16S rRNA gene sequences, showing the relationship between strain Sg163 and members of the genus Streptosporangium.

Numbers at nodes indicate bootstrap percentages (based on 1000 resampled datasets); only values greater than $50 \%$ are given. Accession numbers are given in parentheses. The sequence of Actinomadura madurae DSM $43067^{\mathrm{T}}$ was used as outgroup. Bar, 0.005 substitutions per nucleotide position. 
On the basis of morphological and chemical characteristics, strain $\mathrm{Sg} 163$ was classified in the genus Streptosporangium. The results of comparative studies of physiology and phylogenetic analysis indicated that the isolate was different from known members of Streptosporangium. The high similarity value $(98.3 \%)$ between the strain Sg163 and the type species of Streptosporangium is not surprising. Much higher 16S rRNA similarities have been found between different species of validly described Streptosporangium, such as the type strains of $S$. roseum and S. vulgare (100\%), S. album and S. vulgare (99.8\%), S. album and S. roseum (99.8\%), S. nondiastaticum and S. pseudovulgare (98.8\%), S. longisporum and S. amethystogenes (98.8\%) and S. carneum and S. longisporum (98.6\%). Furthermore, strain Sg163 could be distinguished from the related strains S. album (Quintana and Goodfellow, 2012) and S. canum (Zhang et al., 2009) by phenotypic properties. Eleven differences from closely related Streptosporangium species were recorded and consisted of the use of casein, starch, tyrosine, galactose, inositol, raffinose, sorbitol and xylose, the reduction of nitrate, and the decarboxylation of sodium citrate and sodium oxalate. These results strongly suggest that strain Sg163 may represent a new species of Streptosporangium.

Table 1. Differential characteristics of Streptosporangium sp. Sg163 (1) and the

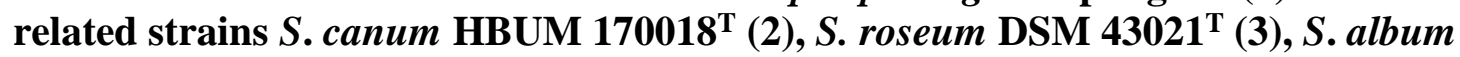
DSM $43023^{\mathrm{T}}(4)$ and $S$. vulgare $\operatorname{DSM} 43802^{\mathrm{T}}(5)$.

\begin{tabular}{|l|l|l|l|l|l|}
\hline \multirow{2}{*}{ Tests/characteristics } & \multicolumn{4}{l}{ Strains } & \multicolumn{2}{l}{} \\
\cline { 2 - 7 } & 1 & 2 & 3 & 4 & 5 \\
\hline Degradation activity & & & & & \\
\hline Casein & + & - & + & - & + \\
\hline Starch & + & - & + & - & + \\
\hline Tyrosin & + & - & + & - & + \\
\hline Galactose & + & - & - & + & + \\
\hline Inositol & - & + & + & - & d \\
\hline Raffinose & - & - & - & + & - \\
\hline Sorbitol & - & - & - & + & - \\
\hline Xylose & + & + & + & - & + \\
\hline Nitrate reduction & + & + & + & - & - \\
\hline Decarboxylation of sodium salts & & & & & \\
\hline Citrate & - & + & - & + & - \\
\hline Oxalate & - & + & nd & - & nd \\
\hline Growth at & & & & & \\
\hline $42^{\circ} \mathrm{C}$ & - & nd & - & - & - \\
\hline $50^{\circ} \mathrm{C}$ & - & nd & - & - & - \\
\hline Sporangium $(\mu \mathrm{m})$ & $6-10$ & $3-6$ & $6-10$ & $6-10$ & $6-10$ \\
\hline Sporangiophores $(\mu \mathrm{m})$ & 10 & nd & 10 & 10 & 10 \\
\hline Spores & $\begin{array}{l}\text { Spherical- } \\
\text { oval }\end{array}$ & Rod & $\begin{array}{l}\text { Spherical- } \\
\text { oval }\end{array}$ & $\begin{array}{l}\text { Spherical- } \\
\text { oval }\end{array}$ & $\begin{array}{l}\text { Spherical- } \\
\text { oval }\end{array}$ \\
\hline
\end{tabular}




\begin{tabular}{|l|l|l|l|l|l|}
\hline \multirow{2}{*}{ Tests/characteristics } & \multicolumn{3}{|l|}{ Strains } & \\
\cline { 2 - 6 } & 1 & 2 & 3 & 4 & 5 \\
\hline Color of spore mass & $\begin{array}{l}\text { White- } \\
\text { pinkish }\end{array}$ & $\begin{array}{l}\text { Whitis } \\
\text { h grey }\end{array}$ & Pink & White & Pink \\
\hline Color of substrate mycelium & $\begin{array}{l}\text { Yellowish } \\
\text { brown }\end{array}$ & Brown & $\begin{array}{l}\text { Red- } \\
\text { orange }\end{array}$ & $\begin{array}{l}\text { Yellowish } \\
\text { brown }\end{array}$ & $\begin{array}{l}\text { Yellowish } \\
\text { brown to } \\
\text { brown }\end{array}$ \\
\hline Diffusible pigments & $\begin{array}{l}\text { Pale } \\
\text { yellow- } \\
\text { brown }\end{array}$ & - & $\begin{array}{l}\text { Red } \\
\text { brown to } \\
\text { purple } \\
\text { brown }\end{array}$ & $\begin{array}{l}\text { Pale } \\
\text { yellow- } \\
\text { brown }\end{array}$ & - \\
\hline
\end{tabular}

+ , positive test; -, negative test; $d, 11-89 \%$ of strains are positive; $n d$, not determined.

Data taken from Quintana and Goodfellow (2012); Zhang et al. (2009); Holt et al. (1994) and Whitham et al. (1993).

\section{Antimicrobial activity}

The antimicrobial activities of the strain $\mathrm{Sg} 163$ against various target microorganisms are shown in Table 2 . The results were expressed as mean \pm standard deviation (SD) from triplicate experiments. The strain exhibited a strong activity against the phytopathogenic and toxigenic fungi tested and two human pathogenic strains of Candida albicans. The antibacterial activity was moderate against Gram-positive bacteria and negative against Gram-negative bacteria.

Table 2. Antimicrobial activity of Streptosporangium sp. Sg163 by the cross-streak method.

\begin{tabular}{|l|l|}
\hline Test organisms & $\begin{array}{l}\text { Distance of } \\
\text { inhibition }(\mathrm{mm})^{\mathrm{a}}\end{array}$ \\
\hline Filamentous fungi & \\
\hline Aspergillus carbonarius M333 & $12.0 \pm 0.9$ \\
\hline Aspergillus westerdijkiae NRRL 3174 & $10.3 \pm 0.7$ \\
\hline Botrytis cinerea B354 & $16.1 \pm 0.5$ \\
\hline Fusarium culmorum F3288 & $13.0 \pm 0.3$ \\
\hline Fusarium graminearum F5883 & $15.0 \pm 0.7$ \\
\hline Fusarium sporotrichioides F13440 & $11.1 \pm 0.7$ \\
\hline Fusarium verticilloides F6442 & $15.3 \pm 1.1$ \\
\hline Geotrichum candidum G669 & $12.0 \pm 0.4$ \\
\hline Umbelopsis ramanniana NRRL 1829 & $25.1 \pm 1.0$ \\
\hline Penicillium citrinum P1843 & $14.0 \pm 0.5$ \\
\hline Penicillium verrucosum P1850 & $30.1 \pm 1.2$ \\
\hline Pythium irregulare PY120 & $10.0 \pm 0.7$ \\
\hline
\end{tabular}




\begin{tabular}{|l|l|}
\hline Test organisms & $\begin{array}{l}\text { Distance of } \\
\text { inhibition }(\mathrm{mm})^{\mathrm{a}}\end{array}$ \\
\hline Sclerotium sclerotiorum S358 & $8.0 \pm 0.2$ \\
\hline Yeasts & \\
\hline Candida albicans C200 & $10.1 \pm 0.1$ \\
\hline Candida albicans C224 & $19.2 \pm 0.2$ \\
\hline Kluyveromyces lactis K258 & $13.1 \pm 0.2$ \\
\hline Rhodotorula mucilaginosa R321 & $8.0 \pm 0.3$ \\
\hline Saccharomyces cerevisiae ATCC 4226 & $34.2 \pm 1.1$ \\
\hline Gram-positive bacteria & \\
\hline Bacillus subtilis ATCC 6633 & $6.0 \pm 0.4$ \\
\hline Listeria monocytogenes CIP 82110 & $2.0 \pm 0.7$ \\
\hline Micrococcus luteus ATCC 9314 & $10.1 \pm 0.7$ \\
\hline Staphylococcus aureus CIP 7625 & $4.0 \pm 0.5$ \\
\hline Gram-negative bacteriab & 0 \\
\hline
\end{tabular}

(a) Values are mean $\pm S D$ of three independent experiments.

(b) No activity obtained against the Gram-negative bacteria: Escherichia coli ATCC 10536, Pseudomonas aeruginosa ATCC 27853 and Klebsiella pneumoniae CIP 8291.

Consequently, Umbelopsis ramanniana and Micrococcus luteus, the most sensitive strains, were selected as the indicator microorganisms for determining the antimicrobial activity in shake culture media.

\section{Fermentation studies}

In liquid media, antifungal and antibacterial activities were observed on all media tested (Figure 2). The maximal antimicrobial activity was observed in ISP2 medium.

During the time course of growth and antibiotic production in ISP2 broth, the antifungal and antibacterial activities were detected on day 3 and 4 of fermentation respectively (Figure 3) and reached the maxima on day 7 . The antifungal activity was stronger than the antibacterial activity. A strong activity against the yeast was detected on day 4 with a maximum recorded on day 8 . These activities were correlated with cell growth. Little variations in $\mathrm{pH}$ were recorded and the maximum $(\mathrm{pH} 8.6)$ was reached on day 8 of fermentation. 

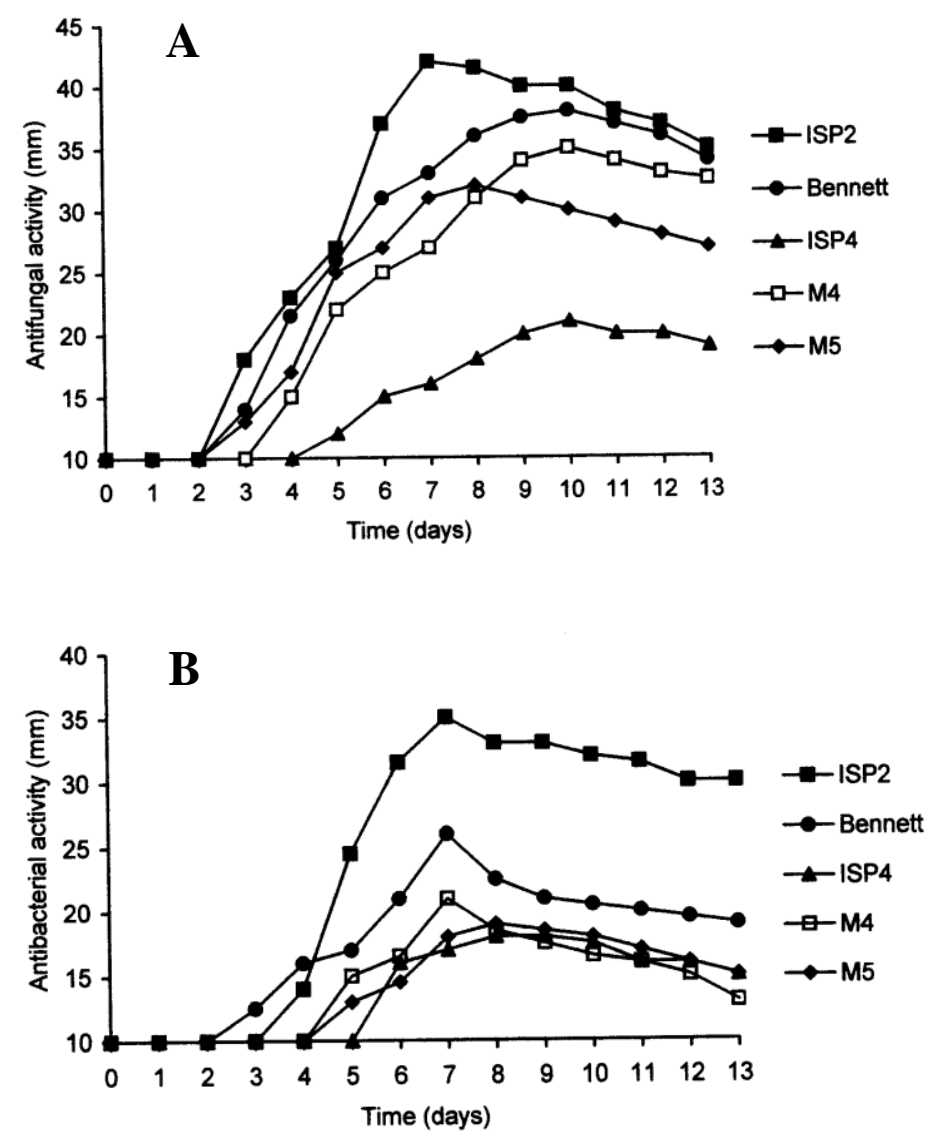

Figure 2. Effect of various culture media on production of antimicrobial activities against Umbelopsis ramanniana (A) and Micrococcus luteus (B) in $500 \mathrm{ml}$ flasks.

Values include the diameter of wells $(10 \mathrm{~mm})$. Media: ISP2, yeast extract - malt extract glucose ; Bennett, meat extract - yeast extract - peptone - glucose ; ISP4, inorganic salts starch ; M4, yeast extract - malt extract - glycerol - peptone; M5, dry yeast - meat extractpeptone - glucose. 


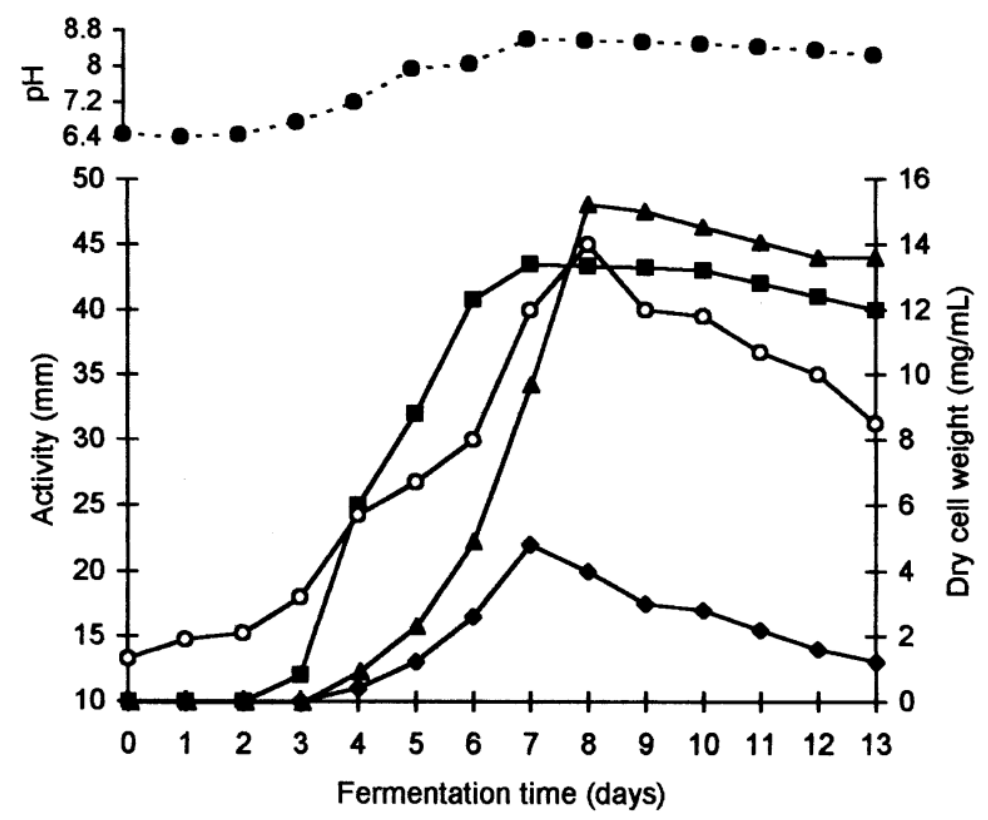

Figure 3. Time course of $\mathrm{pH}$, growth and antibiotic production by Streptosporangium sp. Sg163 in 500 ml flasks.

-, Umbelopsis ramanniana; •, Micrococcus luteus; $\boldsymbol{\Lambda}$, Saccharomyces cerevisiae. Values include the diameter of wells $(10 \mathrm{~mm})$; $\circ$, dry cell weight; $\bullet$, $\mathrm{pH}$.

\section{Extraction and purification of antibiotics}

The cell-free supernatant of 51 shake culture was extracted by $n$-butanol. Recalling that the $n$-butanol was selected as solvent extraction in a preliminary test where four solvents with different polarities were tested. The organic and aqueous phases were bioassayed against Umbelopsis ramanniana, Micrococcus luteus and Saccharomyces cerevisiae and by paper disk method. The activity against the yeast was detected only in the aqueous phase. This work focused on the organic phase, which exhibited activities against filamentous fungi and bacteria. On analytic TLC plates, one spot with both antifungal and antibacterial activity was detected by bioautography at Rf 0.71 . The pooled active band was purified by HPLC. The separated fractions were tested against Umbelopsis ramanniana and Micrococcus luteus. Three active peaks designated C1, C2 and C3 were obtained at the retention times 36.65, 37.70 and 39.49 min, respectively (Figure 4). Each showed both antifungal and antibacterial activity, with $\mathrm{C} 2$ as the major compound. The antifungal activity was stronger than the antibacterial one. 


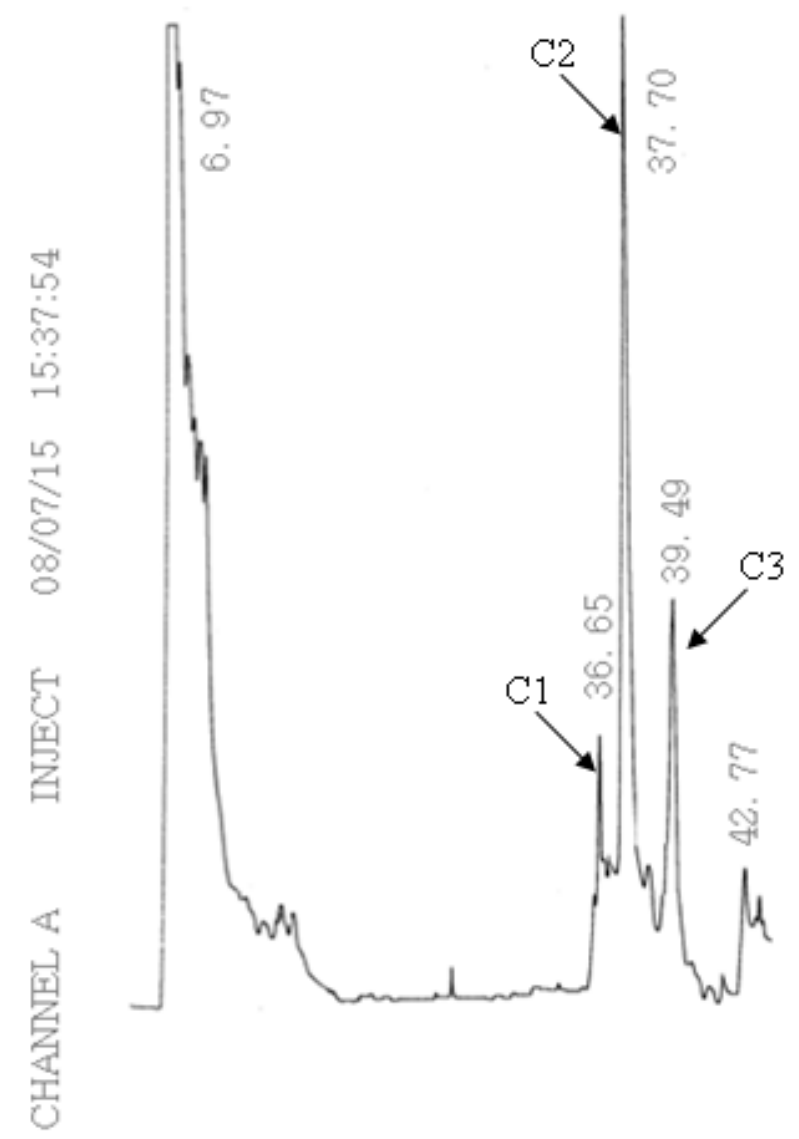

Figure 4. HPLC profile of the first injection showing the active peaks corresponding to the antibiotics $\mathrm{C} 1, \mathrm{C} 2$ and $\mathrm{C} 3$ secreted by the strain Streptosporangium Sg163.

Column C18; gradient system 20 to $75 \%$ v/v methanol in water; detection at $220 \mathrm{~nm}$.

\section{Partial characterization of antimicrobial activities}

The pure antimicrobial compounds $\mathrm{C} 1, \mathrm{C} 2$ and $\mathrm{C} 3$ presented the same $\mathrm{Rf}$ on silica gel TLC plates developed in B.A.W. solvents system. They were revealed positively by the chemical reagents, naphtoresorcinol-sulfuric acid (sugar revelator), formaldehyde-sulfuric acid (visualization reagent of polycyclic aromatic compounds), nitro-4-anilin (revelator of phenols) and ferrous iron chloride (revelator of phenols and hydroxamic acids). Ninhydrin test was negative suggesting the absence of free amines. These results showed for the three molecules the presence of one or more sugars, phenolic moieties and probably other aromatic moieties. These results also suggested that the three molecules were closely related. The UV-vis spectra in methanol (data not 
shown) exhibited absorption maxima at 220 and $351 \mathrm{~nm}$ for C1, 221 and $351 \mathrm{~nm}$ for C2 and 199 and $353 \mathrm{~nm}$ for C3.

The results of chromogenic reactions and UV-vis absorption, and the migration at the same Rf on TLC plates suggested that the three produced compounds C1, C2 and $\mathrm{C} 3$ are similar in their structure.

The infrared spectrum of the major compound $\mathrm{C} 2$ showed $\mathrm{OH}$ groups at 3450 $\mathrm{cm}^{-1}, 1400-1410$ and $1040-1130 \mathrm{~cm}^{-1}, \mathrm{CH}_{3}, \mathrm{CH}_{2}$ and/or $\mathrm{CH}$ groups at 2850-2950 $\mathrm{cm}^{-1}$, $1450-1460 \mathrm{~cm}^{-1}$, and $1375 \mathrm{~cm}^{-1}$. Bands at 1520 and $1625 \mathrm{~cm}^{-1}$ indicated aromatic cycles and at 1640 to $1670 \mathrm{~cm}^{-1}$, ketone group. The nano-electrospray-ionisation mass spectrum (Figure 5) indicated a molecular weight of 492 for the C2 compound.

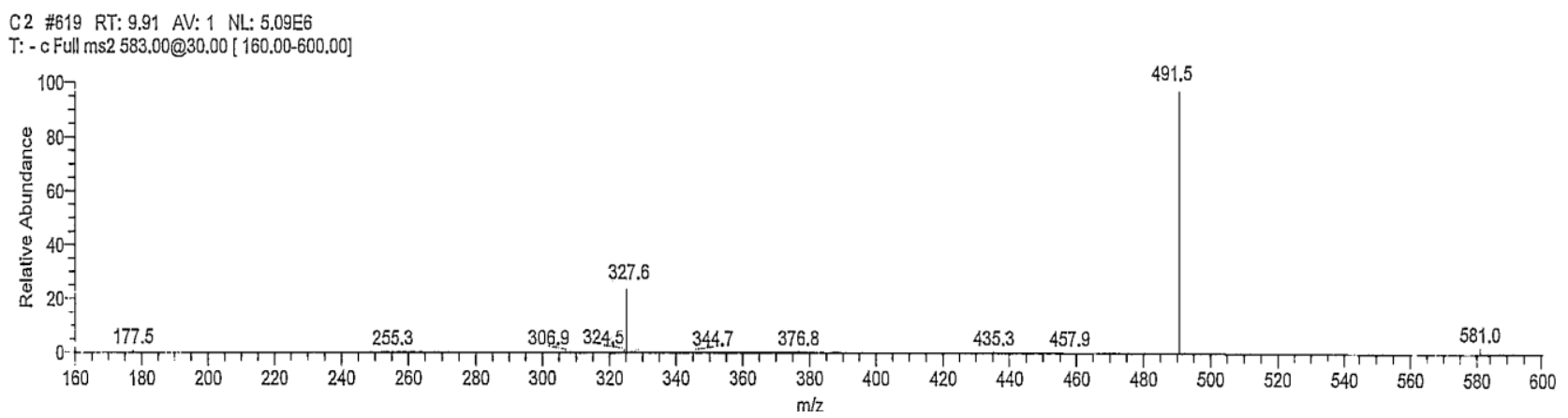

Figure 5. Mass spectrum of C2 compound produced by Streptosporangium sp. Sg163.

The results of chemical revelations and infrared spectrum suggested that the major compound, C2, has a glycosylated aromatic structure. Among antibiotics secreted by strains of Streptosporangium, only sibiromycin and sinefungins are glycosylated aromatics. However, sibiromycin differs from compound $\mathrm{C} 2$ by its activity, which is only antibacterial, its UV-vis $(\lambda \max =230$ and $310 \mathrm{~nm}$ ) and infrared spectra (Hurley et al., 1979). Sinefungins have only antifungal activity and molecular weights between 363 and 422 (Cooper et al., 1990). Numerous glycosylated aromatic antibiotics active against both fungi and bacteria are secreted by actinobacteria (Dictionary of Natural Products, 2017; HeteroCycles, 2017; Buckingham, 1997; Bycroft, 1988; Umezawa, 1988; Berdy et al., 1987). Their comparison with the compound C2 indicated that they are different by colors and/or UV-vis and infrared spectra and molecular weights. NMR analysis is necessary for the structure elucidation of the compound $\mathrm{C} 2$.

Furthermore, the UV-vis spectra indicated that the three active molecules are non-polyenic antifungal compounds because of the absence of the characteristic threeabsorption bands between 260 and $405 \mathrm{~nm}$. The polyene antifungals are potentially toxic and therefore, only few molecules are used in medicine. This drug toxicity along 
with the development of resistance highlights the need for the advent of new effective and less toxic antifungal agents.

\section{CONCLUSION}

In this study, an actinobacterial strain of the genus Streptosporangium showing an interesting antimicrobial activity during the primary screening for antibiotic activities, was identified by morphological, chemical, physiological and molecular methods. The comparative studies revealed that the strain was different from known members of Streptosporangium. DNA-DNA hybridation with the most related species is required to confirm the originality of the strain $\mathrm{Sg} 163$.

Strain Sg163 produced three antibiotics with both antifungal and antibacterial activity. Their partial characterization suggested that they were glycosylated aromatics, a large group of molecules with several chemical structures. Comparison of characteristics of our antibiotics with those cited in the literature did not allow us to identify them. Investigations on the determination of the structures are currently in progress.

\section{ACKNOWLEDGEMENTS}

This work was gratefully supported by the 'Comite'd'Evaluation et de Prospective de Cooperation Inter-universitaire Franco-Algérienne' (CMEP N 02 MDU 564), French Embassy in Algiers.

\section{REFERENCES}

Athalye, M., Goodfellow, M., Lacey, J., and White, R.P. 1985. Numerical classification of Actinomadura and Nocardiopsis. Int. J. Syst. Bacteriol., 35: 86-98.

Athalye, M., Lacey, J. and Goodfellow, M. 1981. Selective isolation and enumeration of actinomycetes using rifampicin. Appl. Bacteriol., 51: 289-297.

Badji, B., Zitouni, A., Mathieu, F., Lebrihi, A. and Sabaou, N. 2006. Antimicrobial compounds produced by Actinomadura sp. AC104 isolated from an Algerian Saharan soil. Can. J. Microbiol., 52: 373-382.

Becker, B., Lechevalier, M.P., Gordon, R.E., Lechevalier, H.A. 1964. Rapid differentiation between Nocardia and Streptomyces by paper chromatography of whole-cell hydrolysates. Appl. Microbiol., 12: 421-423.

Berdy, J., Aszalos, A. and Mc Nitt, K.L. 1987. CRC Handbook of antibiotic compounds. Vol. XIII. Microbial metabolites, Parts 1, 2, 3., CRC Press Florida, USA.

Betina, V. 1973. Bioautography in paper and thin layer chromatography and its scope in the antibiotic field. J. Chromatogr., 78: 41-51.

Boubetra, D., Sabaou, N., Zitouni, A., Bijani, C. and Lebrihi, A. et al. 2013. Taxonomy and chemical characterization of new antibiotics produced by Saccharothrix SA198 isolated from a Saharan soil. Microbiol. Res., 168: 223-230. 
Boudjella, H., Bouti, K., Zitouni, A., Mathieu, F. and Lebrihi, A. et al. 2007. Isolation and partial characterization of pigment-like antibiotics produced by a new strain of Streptosporangium isolated from an Algerian soil. J. Appl. Microbiol., 103: 228-236.

Boudjella, H., Zitouni, A., Coppel, Y., Mathieu, F. and Monje, M.-C. et al. 2010. Antibiotic R2, a new angucyclinone compound from Streptosporangium sp. Sg3. J. Antibiot., 63: 709-711.

Buckingham, J. 1997. Dictionary of Natural Products, ed. by Chapman and Hall, London.

Bycroft, B.W. 1988. Dictionary of antibiotics and related substances. Chapman and Hall, London.

Cooper, R., Das P., Federbush, C., Mierzwa, R. and Patel., et al. 1990. Characterization of peptidyl-nucleoside antifungal antibiotics from fermentation broth. J. Ind. Microbiol., 5: 1-8.

Demain, A.L. and Sanchez, S. 2009. Microbial drug discovery: 80 years of progress. $J$. Antibiot., 62: 5-16.

Dictionary of Natural Products. 2017. Online chemical database. CRC Press, Taylor \& Francis Group.

http://dnp.chemnetbase.com/faces/chemical/ChemicalSearch.xhtml

Felsenstein, J. 1985. Confidence limits on phylogenies: an approach using the bootstrap. Evol., 39: 783-791.

Fischbach, M.A. and Walsh, C.T. 2009. Antibiotics for emerging pathogens. Science, 325: 1089-1093.

Genilloud, O. 2014. The re-emerging role of microbial natural products in antibiotic discovery. Ant. V. Leeuw., 106: 173-188.

Genilloud, O., Gonzales I., Salazar O., Martin J. and Tormo J.R., et al. 2011. Current approaches to exploit actinomycetes as a source of novel natural products. $J$. Ind. Microbiol. Biotechnol., 38: 375-389.

Gilpin, M.L., Fulston, M., Payne, D., Cramp, R. and Hood, I. 1995. Isolation and structure determination of two novel phenazines from a Streptomyces with inhibitory activity against metallo-enzymes, including metallo- $\beta$-lactamase. $J$. Antibiot., 48: 1081-1085.

Goodfellow, M. 1971. Numerical taxonomy of some nocardioform bacteria. J. Gen. Microbiol., 69: 33-90.

Gordon, R.E. and Barnett, D.A. 1977. Resistance to rifampicin and lysozyme of strains of some species of Mycobacterium and Nocardia as a taxonomic tool. Int. J. Syst. Bacteriol. 27: 176-178.

Gordon, R.E., Barnett, D.A., Handarhan, J.E. and Hor-Nay-Pang, C. 1974. Nocardia coeliaca, Nocardia autotrophica and the nocardin strains. Int. J. Syst. Bacteriol., 24: 54-63.

Hayakawa, M. and Nonomura, H. 1987. Humic acid-vitamin agar, a new medium for the selective isolation of soil actinomycetes. J. Ferm. Technol., 65: 501-509.

HeteroCycles. 2017. Natural Products with Heterocyclic Ring System. Published online by The Japan Institute of Heterocyclic Chemistry. 
https://www.heterocycles.jp/newlibrary/natural_products/structure

Holt, J.G., Krieg, N.R., Sneath, P.H.A., Staley, J.T. and Williams, S.T. 1994. Bergey's Manual of Determinative Bacteriology, 9th ed., ed. by Williams and Wilkins, Baltimore.

Hurley, L.H., Lasswell, W.L., Malhotra, R.K. and Das, N.V. 1979. Pyrrolo[1,4]benzodiazepine antibiotics. Biosynthesis of the antitumor antibiotic sibiromycin by Streptosporangium sibiricum. Biochem., 18: 4225-4229.

Inahashi, Y., Iwatsuki, M., Ishiyama, A., Namatame, M. and Nishihara-Tsukashima, A. et al. 2011. Spoxazomicins A-C, novel antitrypanosomal alkaloids produced by an endophytic actinomycete, Streptosporangium oxazolinicum K07-0460(T). J. Antibiot., 64(4): 303-307.

Jukes, T.H., Cantor, C.R. 1969. Evolution of protein molecules. In Mammalian Protein Metabolism, ed. by Munro H.N., vol. 3. Academic Press, New York, pp. 21-132.

Kim, O.S., Cho, Y.J., Lee, K., Yoon, S.H. and Kim, M. et al. 2012. Introducing EzTaxon-e: a prokaryotic 16S rRNA gene sequence database with phylotypes that represent uncultured species. Int. J. Syst. Evol. Microbiol., 62: 716-721.

Kurtböke, D.I. 2012. Biodiscovery from rare actinomycetes: an ecotaxonomical perspective. Appl. Microbiol. Biotechnol., 93: 1843-1852.

Lechevalier, M.P., De Bievre, C. and Lechevalier, H.A. 1977. Chemotaxonomy of aerobic actinomycetes: phospholipid composition. Biochem. Syst. Ecol., 5: 249260.

Lechevalier, M.P. and Lechevalier, H.A. 1970. Chemical composition as a criterion in the classification of aerobic actinomycetes. Int. J. Syst. Bacteriol., 20: 435-443.

Liu, D., Coloe, S., Baird, R. and Pedersen, J. 2000. Rapid mini-preparation of fungal DNA for PCR. J. Clin. Microbiol., 38: 471.

Marchal, N., Bourdon, J.L. and Richard, C.1. 1987. Les milieux de culture pour l'isolement et l'identification biochimique des bactéries, ed. by Doin, Paris, pp. 67-122.

Meklat, A., Bouras, N., Zitouni, A., Mathieu, F. and Lebrihi, A. et al. 2013. Actinopolyspora mzabensis sp. nov., a halophilic actinomycete isolated from an Algerian Saharan soil. Int. J. Syst. Evol. Microbiol., 63: 3787-3792.

Minnikin, D.E., Patel, P.V., Alshamaony, L. and Goodfellow, M. 1977. Polar lipid composition in the classification of Nocardia and related bacteria. Int. J. Syst. Bacteriol., 27: 104-117.

National Bureau of Standards 1964. ISCC-NBS Colorname Charts Illustrated with Centroid Colors (supplement to National Bureau of Standards USA Circular 553). Gaithersburg, MD: National Bureau of Standards, USA.

Nonomura, H. and Ohara, Y. 1969a. Distribution of actinomycetes in soil. VI. A culture method effective for both preferential isolation and enumeration of Microbispora and Streptosporangium strains in soil. Part 1. J. Ferm. Technol., 47: 463-469.

Nonomura, H. and Ohara, Y. 1969b. Distribution of actinomycetes in soil. VII. A culture method effective for both preferential isolation and enumeration of 
Microbispora and Streptosporangium strains in soil. Part 2. Classification of the isolates. J. Ferm. Technol., 47: 701-709.

Omura, S., Eda, S., Funayama, S., Komiyama, K. and Takahashi, Y. et al. 1989. Studies on a novel antitumor antibiotic, phenazinomycin: taxonomy, fermentation, isolation, and physico-chemical and biological characteristics. J. Antibiot., 42: 1037-1042.

Platas, G., Pelaez, F., Collado, J., Martinez, H., Diez, M.T. 1999. Nutritional preferences of a group of Streptosporangium soil isolates. J. Biosci. Bioeng., 88(3): 269-275.

Quintana, E.T. and Goodfellow, M. 2012. Genus 1. Streptosporanium Couch 1995a, $145^{\mathrm{AL}}$ emend. Stackebrandt Kroppenstedt, Janke, Kemmering and Gürtler 1994, 268. In Bergey's manual of systematic bacteriology, ed. By Goodfellow, M., Kämpfer, P., Busse, M.J., Trujillo, M., Suzuki, K.E., Ludwig, W. and Whitman, W.B., 2nd ed., vol 5, Springer, New York. pp. 1807-1824.

Saitou, N. and Nei, M. 1987. The neighbor-joining method: a new method for reconstructing phylogenetic trees. Mol Biol. Evol., 4: 406-425.

Shirling, E.B. and Gottlieb, D. 1966. Methods for characterization of Streptomyces species. Int. J. Syst. Bacteriol., 16: 3313-3340.

Sierra, G. 1957. A simple method for the detection of lipolytic activity of microorganisms and some observations on the influence of the contact between cells and fatty substrates. J. Microbiol. Serol., 23: 15-22.

Solecka, J., Zajko, J., Postek, M. and Rajnisz, A. 2012. Biologically active secondary metabolites from actinomycetes. Cent. Eur. J. Biol., 7(3): 373-390.

Tamura, K., Peterson, D., Peterson, N., Stecher, G. and Nei, M. et al. 2011. MEGA5: molecular evolutionary genetics analysis using maximum likelihood, evolutionary distance, and maximum parsimony methods. Mol. Biol. Evol., 28: 2731-2739.

Thompson, J.D., Higgins, D.G. and Gibson, T.J. 1994. CLUSTAL W: improving the sensitivity of progressive multiple sequence alignment through sequence weighing, position specific gap penalties and weight matrix choice. Nucleic Acids Res., 22: 4673-4680.

Tiwari, K. and Gupta, R.K. 2012. Rare actinomycetes: a potential storehouse for novel antibiotics. Crit. Rev. Biotechnol., 32(2): 108-132.

Tiwari, K. and Gupta, R.K. 2013. Diversity and isolation of rare actinomycetes: an overview. Crit. Rev. Microbiol., 39(3): 256-294.

Umezawa, H. 1988. Low molecular weight enzyme inhibitors and immunodifiers. In Actinomycetes in Biotechnology, ed. by Goodfellow, M., Williams, S.T., Mordarski M., Pergamon Press, Oxford, pp. 285-325.

Warren, H.B., Prokop, J.F. and Grundy, W.E. 1955. Non synthetic media for antibiotic producing actinomycetes. Antib. Chemother., 5: 6-12.

Whitham, T.S., Athalye, M. Minnikin, D.E. and Goodfellow, M. 1993. Numerical and chemical classification of Streptosporangium and some related actinomycetes. Antonie van Leeuwenhoek 64: 387-429. 
Williston, E.H., Zia-Walrath, P. and Youmans, G.P. 1947. Plate methods for testing antibiotic activity of actinomycetes against Virulent human type Tubercle Bacilli. J. Bacteriol., 54: 563-568.

Zhang, L.P., Zhang, L.M. and Zhang, X.M. 2009. Streptosporangium canum sp. nov., isolated from soil. Int. Syst. Evol. Microbiol., 59: 1715-1719.

Zitouni, A., Boudjella, H., Mathieu, F., Sabaou, N. and Lebrihi, A. 2004a. Mutactimycin PR, a new anthracycline antibiotic from Saccharothrix sp. SA 103. I. Taxonomy, fermentation, isolation and biological activities. J. Antibiot., 57: 367-372.

Zitouni, A., Lamari, L., Boudjella, H., Badji, B. and Sabaou, N., et al. 2004b. Saccharothrix algeriensis sp. nov., isolated from Saharan soil. Int. Syst. Evol. Microbiol., 54: 1377-1381. 